\title{
El Boom y el fracaso de los intelectuales. Sobre Conversación en la Catedral (1969) de Vargas Llosa y Cien años de soledad (1967) de García Márquez
}

\begin{abstract}
Resumen
El debate en torno al papel de los intelectuales tiene un lugar central en el Boom de la Literatura Latinoamericana. Por un lado, porque es un momento en que los escritores saltan a la esfera pública e intervienen en ámbitos que exceden lo literario. Por otro, porque ha sido uno de los temas que ha ocupado a la crítica en su afán de adscribir el fenómeno al mercado o a las circunstancias políticas de América Latina.

Bajo el supuesto de esa centralidad, el presente artículo busca desentrañar las representaciones del intelectual que aparecen en dos novelas del período: Conversación en la Catedral (1969) de Mario Vargas Llosa y Cien años de soledad (1967) de Gabriel García Márquez. En ellas aparecen elementos y problemáticas presentes en los debates que les son contemporáneos con una mirada más amplia que la que opone al escritor y el político (o al intelectual y el revolucionario). Las tareas propias del letrado y la relación con la esfera pública y con las masas definen a los dos personajes principales a partir de los que se puede reconstruir una definición del intelectual.
\end{abstract}

Palabras claves

intelectuales, Boom de la literatura latinoamericana, Vargas Llosa, García Márquez.

\begin{abstract}
The debate around the role played by intellectuals is key to the study of the Latin American Literary Boom. On the one hand, it's a time in which writers begin to appear publicly and to participate in extraliterary matters. On the other, it has been one of the subjects considered by critics when dealing with the nature of the phenomenon, whether a market product or a result of political circumstances.

With that centrality as its starting point, this article aims to expose some representations of intellectuals appearing in two boom novels: Mario Vargas Llosa's Conversación en la Catedral
\end{abstract}


(1969) and Gabriel García Marquez' Cien años de soledad (1967). Both contain elements similar to those considered in contemporary debates but offer a broader view than the recurrent opposition between writers and politicians (or intellectuals and revolutionaries). The two main characters are defined by scholarly tasks, relationships with the public sphere and with the masses, all of which allow us to reconstruct a definition of the intellectual.

Keywords intellectuals- Latin American Literary Boom-Vargas Llosa- García Márquez.

Uno de los grandes temas que rodean al llamado Boom de la Literatura Latinoamericana es el de los intelectuales. Según se mire, existen varias inflexiones de la misma cuestión. La transformación de los escritores en intelectuales ha sido considerada de modos diversos, desde un resultado de la exposición pública a través de los medios que contribuían a su profesionalización - concomitante de la postura que ve el Boom como un fenómeno de mercadohasta la forma en que fijaron su inserción en el mundo y ligaron las cuestiones literarias a las políticas en un contexto latinoamericano que parecía reclamar toda la atención posible - a su vez, ligada a las posiciones que ven el Boom como un fenómeno cultural favorecido y amparado por la Revolución Cubana. ${ }^{1}$ La oposición es simplista pero no viene al caso. Las formas de participación y los posicionamientos de los escritores de la época como colectivo y de cada uno en particular han sido visitadas reiteradamente como también lo han sido las contradicciones generadas por la asunción de un nuevo rol en la esfera pública sin dejar de lado la actividad que los definía como escritores- y de la que, de más está decir, dependía su relevancia en la esfera pública.

${ }^{1}$ Un análisis de esa controversia puede leerse en Mercedes Alonso y Gastón Gallo. "El boom de la literatura latinoamericana”. Marcela Croce, ed. Latinoamericanismo: Una utopía intelectual. Buenos Aires: Simurg, 2011. 147-174. 
No es mi intención volver sobre esa problemática que es histórica y tiene manifestaciones concretas ${ }^{2}$ sino indagar en las representaciones de intelectuales presentes en la literatura del momento bajo el supuesto de que allí se negocian algunos de los significados que se están poniendo en juego en el mundo real. La elección podría haber sido otra, pero por su relevancia como textos y por el lugar central que ocupan los intelectuales en ellas me concentraré en Conversación en La Catedral (1969) de Mario Vargas Llosa y Cien años de soledad (1967) de Gabriel García Márquez. ${ }^{3}$ No es que las novelas sean ejercicios programáticos destinados a legislar sobre la función de los intelectuales, ni siquiera que sean descripciones del papel que estos están jugando en su contemporaneidad sino simplemente que las figuras de intelectuales que aparecen en ellas permiten pensar más allá de los estrechos márgenes que oponen al escritor y el político (o al intelectual y el revolucionario).

Antes de emprender esa tarea sería necesario definir qué es un intelectual. Evidentemente, la variedad de las definiciones posibles, sumada a la complejidad de sus fundamentos, hace imposible llegar a una respuesta definitiva. Por otra parte, como en la construcción de esos personajes hay una apuesta por la definición de lo que es y lo que hace un intelectual, no sería del todo provechoso establecerlo de antemano. Sin embargo, sí es posible anticipar qué entiendo aquí por intelectual, qué es lo que permite identificar como intelectuales a algunos de los personajes que aparecen en los textos.

En un libro dedicado a explorar esta cuestión, Carlos Altamirano señala que el concepto de intelectual no tiene un significado establecido, que es múltiple como el conjunto social que se identifica con él. La formulación recuerda a la idea de Zygmunt Bauman de que "intelectual” es siempre una autodefinición: una extensión del deber ser que un intelectual o un conjunto de ellos se impone a sí

${ }^{2}$ Un desarrollo desde esta perspectiva puede encontrarse en el ya clásico libro de Claudia Gilman. Entre la pluma y el fusil. Debates y dilemas del escritor revolucionario en América Latina. Buenos Aires: Siglo XXI, 2003.

${ }^{3}$ Si bien la de Vargas Llosa no es la novela con la que se coloca dentro del Boom -que sería la primera, La ciudad y los perros (1959)-, está cronológicamente más cerca de la de García Márquez y trabaja centralmente la figura del intelectual. 
mismo - y por lo tanto es prescriptiva o al menos valorativa. Ahora bien, después del hacer un recorrido por varias perspectivas sobre los intelectuales, Altamirano arma una suerte de resumen de las funciones de los intelectuales en la sociedad: situados en la esfera de la cultura, el arte, la literatura, los intelectuales son creadores de doctrina u operadores del mensaje ideológico (como profesores o periodistas, por ejemplo). La formulación es útil porque permite identificar algunos rasgos sin entrar en definiciones. Otra posibilidad, aún más general pero mucho más provocativa, es la "definición reducida" que hace Edward Said: "Los intelectuales trafican con ideas" (113).

Las dos aproximaciones permiten focalizar en los personajes intelectuales de las dos novelas. Esto implica dejar de lado muchos aspectos, pero pretendo amparar el recorte excesivo de la problemática intelectual en las innumerables lecturas anteriores. Conversación en la Catedral gira en torno a Santiago Zavala, que es periodista - uno de los operadores del mensaje ideológico de Altamiranoporque fracasa como escritor, como militante, como estudiante de Derecho. La trama de la novela es la indagación en ese fracaso inserto en un fracaso mayor a través del paralelo que se traza desde la primera página: cuándo se jodió él y cuándo se jodió el Perú. En Cien años de soledad la cuestión intelectual se vuelve central si se coloca el foco en Melquíades y sus manuscritos. A partir de esa presencia, que es fundacional en Macondo puesto que los gitanos llevan los primeros signos del progreso -que siempre viene con los viajeros-, los intentos por descifrar los manuscritos forman una trama que llega hasta el final. En el medio, se organiza la vida intelectual de la familia Buendía. La clase de los Aurelianos, como los llama Ludmer, es la clase de los intelectuales que alternativamente se dedican al estudio y a la política.

Hay diferencias fundamentales entre las novelas que es preciso esclarecer. En primer lugar, ocupan posiciones diferentes dentro del Boom - la de García Márquez es la más representativa del fenómeno en lo que tuvo de éxito de mercado y de lectura mientras que la de Vargas Llosa no es la novela con la que se consagra dentro del Boom aunque sí la más rescatada por fuera de ese 
fenómeno. ${ }^{4}$ En segundo lugar, el período de dos años que las separa marca una situación diferente para el escritor-intelectual latinoamericano. En ese brevísimo lapso temporal se comienzan a ver los desajustes que van a estallar en el remanido “caso Padilla"; entre ellos el Congreso Cultural de La Habana de enero de 1968 donde se tendieron los lineamientos fundamentales de lo que debería ser un intelectual en la Revolución. No pretendo establecer una relación punto por punto de las representaciones de los intelectuales en las novelas y la situación de los intelectuales en el mundo, pero no es un dato menor.

En lo que hace a lo estrictamente literario, las dos novelas presentan una diferencia radical en su configuración espacio-temporal: mientras Conversación se centra en poco más de una década del pasado reciente del Perú -el gobierno de Manuel Odría (1950-1956) y lo inmediatamente anterior y posterior-, Cien años cubre algunos siglos de un lugar imaginario que, aunque se dejen asociar al pasado latinoamericano desde la Conquista hasta principio del siglo $\mathrm{XX}$, quedan fuera de la temporalidad histórica. ${ }^{5}$ Esta diferencia determina las definiciones de los intelectuales o las funciones que cumplen en las sociedades de cada una de las novelas. Por otro lado, mientras Cien años gira en torno a un texto escrito, Conversación se construye sobre la ficción de oralidad. ${ }^{6}$ La diferencia está marcada por los sujetos involucrados en cada caso: lo que leen los Aurelianos es un texto producido por otro intelectual; lo que tiene que descifrar Santiago Zavala es la información que aporta Ambrosio, con el que hay una marcadísima diferencia de clase.

${ }^{4}$ Es conocida la referencia que el mismo Vargas Llosa hace en el "Prólogo" de 1998 de que sería la única que rescataría del fuego (Vargas Llosa, Conversación).

5 Sobre la relación entre tiempo histórico y tiempo mítico en Cien años de soledad véase el artículo de Volkening quien plantea que la novela es el relato de la conversión de la historia de los Buendía en un mito.

${ }^{6}$ Lo que no niega el hecho de que Cien años de soledad utilice, como señala Rama, un procedimiento propio del relato oral como la coordinación de anécdotas mientras que la novela de Vargas trabaje con la subordinación que depende totalmente de la escritura. Lo que propongo es otro foco, orientado a los materiales ficcionales y no a los procedimientos narrativos. De todos modos, además de la yuxtaposición, la novela de García Márquez establece una suerte de cajas chinas temporales en las remisiones hacia el futuro del pasado como en la primera frase. 
Esas relaciones son fundamentales para la política de las novelas y para el modo en que representan a sus intelectuales. Si hay una cuestión que atraviesa todas las teorizaciones sobre lo que son los intelectuales es la relación que existe entre su formación y participación profesional y específica en la esfera de la cultura y su intervención en el mundo. Desde el compromiso sartreano al "legislador" de Bauman que funda su autoridad en la cultura para proyectar un modelo de sociedad realmente realizable; desde los ideólogos de Marx y Engels hasta la idea de Said de la conciencia crítica cuyo deber es estar cerca de la realidad, los intelectuales se definen por ese pasaje de una esfera a otra y lo que está siempre en juego es cómo eso sucede y con qué sentido o qué objetivos. Las dos novelas proponen modos de estar en el mundo de los intelectuales, funciones que los insertan en la sociedad. La tarea de Santiago Zavala y la de Aureliano Babilonia es descifrar: la historia del padre de Santiago, que es a la vez vía de acceso a la trama política del Perú, o la profecía sobre la estirpe de los Buendía, que es el relato mítico de los orígenes de, al menos, una región de América Latina. La contradicción entre la actividad intelectual y la acción política, que es una problemática fundamental para la intelectualidad y especialmente en el momento en que se escriben estas novelas, es la dualidad que existe entre los aurelianos y que está también presente en la biografía de Santiago Zavala. Las dos novelas ofrecen soluciones imaginarias -que no quiere decir felices- para problemáticas muy concretas de los intelectuales: la función social, la relación con la política, los modos de estar y hacerse cargo del mundo sin perder la especificidad de la esfera cultural.

\section{Comienzos, fuentes, puntos de partida}

Cien años de soledad y Conversación en la catedral se organizan en torno al desciframiento. En Conversación, la trama de historias personales que dan forma a la historia peruana, bajo el supuesto balzaciano que está en el epígrafe de 
la novela, ${ }^{7}$ está montada sobre la conversación en la que Santiago plantea la pregunta -cuándo se jodió él, la pregunta por su propio pasado- y sonsaca a Ambrosio de versiones y testimonios: el intercambio está fundado en la diferencia de clase y es necesariamente desigual. Las respuestas de Ambrosio son la nueva articulación de su subalternidad. La epidemia de rabia que reúne a los dos personajes también los ubica en dos extremos, Ambrosio es empleado de la perrera que se lleva al perro de Santiago. Él, por otro lado, es responsable de redactar las editoriales que inflan la epidemia de rabia, como si hasta esta pequeña desgracia doméstica fuera consecuencia directa de sus elecciones, cuya reconstrucción conduce el relato hacia un pasado más remoto. Tras el fracaso de la militancia de la juventud, de las aspiraciones literarias que ni siquiera intenta y el ingreso al periodismo, Santiago prefiere escribir esas editoriales triviales que hacerlo "sobre Cuba o Vietnam" (Conversación 17). Resulta paradójico que precisamente en esa banalidad se juegue el desarrollo de la novela. Son esos editoriales los que motivan el "secuestro" del perro de Santiago, el encuentro con Ambrosio, la conversación en La Catedral. Hay allí una comprobación irónica de la utilidad del papel del intelectual: ni en lo más trivial las palabras caen en el vacío.

Sin embargo, la conversación no es una sola. No sólo incluye el relato de otras anteriores que se van subordinando sino que hay conversaciones posteriores que cuentan hechos también posteriores en los que Santiago es periodista de policiales. Desde esa nueva función se vuelven útiles varios de los datos y los personajes dispersos en la otra parte de la historia que se aglutinan en torno a la víctima. Hortensia, La Musa, fue amante de Cayo Bermúdez, encargado de las fuerzas represivas durante el gobierno de Odría y empleadora de Amalia, que es ex empleada de Fermín, el padre de Santiago, y esposa de Ambrosio. Todo lo que él revela, antes y después, puede ser leído como parte de la investigación periodística. Es más, en Conversación se puede ver una estructura policial en el

7 "Il faut avoir fouillé tout la vie sociale pour être un vrai romancier, vu que le roman est l'histoire privée des nations" (Vargas Llosa, Conversación 11). 
modo en que la información se va acumulando de a retazos hasta llegar a la reconstrucción de los hechos. O sea que la indagación de Santiago es doble: es profesional cuando se ocupa de las circunstancias del crimen de La Musa y es personal cuando es sobre su historia familiar y su fracaso personal. El caso se resuelve cuando coinciden los dos relatos.

En Cien años el objeto del desciframiento son los manuscritos de Melquíades. No sólo se trata de un texto escrito sino que su productor también ocupa una posición muy diferente a la de Ambrosio; más que por debajo se ubica por encima de todos los Buendía, como iniciador. Los gitanos con los que viene Melquíades son parte del origen de Macondo y, a diferencia de los gitanos que aparecen después, los que traen el hielo, estos traen el progreso. Los tres objetos que Melquíades le da a José Arcadio Buendía lo marcan como patriarca: el imán que pretende usar para buscar oro; la lupa para la guerra y los instrumentos de navegación que le permiten tener el conocimiento del territorio. Con las tres cosas se puede fundar una nación. Sin embargo, en el fracaso de las dos primeras tentativas se empieza a perfilar su propio papel como intelectual y el modo en que van a aparecer todos los otros intelectuales de la novela. Además de revelar que Macondo es un lugar desconectado del mundo donde todo empieza desde cero, ${ }^{8}$ el descubrimiento de que la tierra es redonda es el resultado de un pensamiento que opera por "pura especulación” (García Márquez 10). Por oposición al gitano que "parecía conocer el otro lado de las cosas" (10-11) porque viaja, todos los Buendía aprenden y piensan encerrados en el laboratorio que también es obra de Melquíades y que permanece siempre intocado por el polvo y la destrucción hasta el cataclismo final.

Ese legado es una de las formas en que Melquíades, como señala Ludmer, establece las condiciones de posibilidad de la narración porque crea la "zona literatura". Melquíades es el intelectual originario que genera una descendencia. De hecho, su función como iniciador pasa a las diferentes generaciones de

${ }^{8}$ En el otro extremo de la historia, Aureliano Babilonia alcanza "los conocimientos básicos del hombre medieval" (CAS: 299). 
Buendía que se transforman en maestros unos de otros o, como en el caso de Arcadio, en maestro como función oficial. Su otra intervención, que depende de la primera, son los manuscritos. Su sola existencia determina la formación de los “intelectuales” Buendía, que, como Santiago Zavala, se dedicarán a descifrar. A la vez, abren otra posibilidad de la tarea intelectual ligada a la memoria. Cuando sea finalmente descifrada, la profecía será leída como una historia porque salvo la destrucción final de Macondo todos los otros hechos ya han tenido lugar. Los manuscritos ocupan así el lugar que no logran ocupar los intentos fallidos de conjurar la peste: los cartelitos con nombres y funciones que Aureliano le cuelga a todas las cosas y su segunda forma, más compleja, la "máquina de la memoria" ideada por José Arcadio que está más cerca de la escritura de la historia -aunque individual- que de una utilidad práctica. En su segunda intervención importante, Melquíades es el que cura la peste del insomnio que trae aparejado el olvido, los manuscritos profundizan esta tarea, que también estaba en otro de los avances tecnológicos traídos por el gitano, el daguerrotipo. Antes de su aparición, la memoria sólo se conservaba oralmente en los cantos del trovador Francisco el Hombre. Melquíades inventa la escritura y una función para los Buendía: convertirse en lectores para conservar la memoria del pueblo.

\section{Las armas y las letras: nuevas inflexiones}

Uno de los problemas de los intelectuales es que para serlo necesitan ciertas condiciones materiales de las que no se ocupan. Los inventos y los estudios de José Arcadio Buendía son posibles gracias a la actividad manual de los otros; mientras él se encierra en el laboratorio, el orden de la casa (que es como el mundo) se sostiene porque "Úrsula y los niños se partían el espinazo en la huerta." (García Márquez 9) En Conversación en la Catedral esa misma relación se codifica en términos de clase. Desde el episodio inicial, en el que Santiago supone portadores de un mal esencial a quienes tienen en la perrera un medio de subsistencia -“A los recogedores se les pagaba por animal, a veces 
abusaban, qué se le iba a hacer, era la lucha por los frejoles" (21)- toda la novela puede ser leída como la narración de esa incomprensión: el recorrido por las diferentes maneras en que el intelectual imagina al pueblo.

En un principio es la Universidad de San Marcos en oposición a la Católica que es la opción burguesa y paterna. Allí quiere ir Santiago porque supone que allí va el pueblo; se enamora de Aída, que es pobre y comunista; se hace militante porque quiere armarse con "la ideología de la clase obrera" (Vargas Llosa, Conversación 84). Pero en el mismo momento en que su rebeldía adolescente lo lleva a San Marcos, sus ansias adolescentes lo hacen darle yobimbina a la empleada de su casa -Amalia - para aprovecharse de ella. Contradicciones burguesas: el primer fracaso, el de la militancia, es que no puede ser pueblo, no tanto porque su padre lo saque de la cárcel donde está con sus compañeros sino porque no entiende, porque el pueblo sólo le interesa si es imaginario.

Las caras ¿recias, dignas, graves, sobrias? De los hombres que avanzaban por las veredas embutidos en overoles y sacones grises, y oyó sus diálogos ¿solidarios, parcos, clandestinos? Y pensó obreros, y pensó comunistas y decidió no soy bustamantista, no soy aprista, soy comunista. (74)

Las oposiciones en Cien años son varias. La primera era la del trabajo intelectual y el trabajo manual -José Arcadio y Úrsula. En un orden más general, la función de Úrsula se opone no al trabajo intelectual de su marido sino a su función pública. Mientras él "ponía en orden el pueblo", ella "consolida el patrimonio doméstico" (García Márquez 38) con la producción de animalitos azucarados. La división del trabajo es constitutiva de la organización social -y eso es lo que los Buendía tratan de hacer permanentemente en Macondo- pero no necesariamente está estructurada en base al género, como puede parecer acá. Aunque las mujeres de la novela aparezcan como figuras opuestas a las de los 
hombres, ${ }^{9}$ los roles tradicionales pueden invertirse y hacia el final de la historia es Aureliano Babilonia quien se encarga de las tareas domésticas ante la incapacidad de Fernanda. Esas funciones públicas de los Buendía también entran en contradicción con sus funciones intelectuales. Josefina Ludmer estableció la oposición básica que segmenta a los hombres Buendía en un conjunto "mente" (a partir de Aureliano) y un conjunto "cuerpo" (José Arcadio). No me interesa continuar indagando en esa oposición sino en las contradicciones que se dan dentro del primer conjunto: las formas de interacción entre la actividad política y la mental que Ludmer también registraba y que son fundamentales para analizar la representación de los intelectuales.

A diferencia de la distinción anterior, que aparece recién en el par de hijos varones, esta otra dualidad también está en José Arcadio Buendía. Es la llegada de Melquíades con sus inventos lo que provoca el pasaje de "patriarca juvenil" (14) José Arcadio había tenido un sueño profético sobre la fundación de Macondo, había dirigido la peregrinación y la fundación, etc. - a intelectual, identidad que asume hasta el período de esplendor de Macondo, cuando vuelve a tomar las riendas de la organización política y social, lo cual incluye las políticas sanitarias durante la peste del insomnio. En ese episodio, y únicamente allí, las funciones se reúnen: además de evitar el contacto entre enfermos y sanos o imponer el uso del silbato para identificar a los visitantes, que son funciones políticas, José Arcadio inventa la máquina de la memoria, que es también la escritura de la historia y por lo tanto una tarea intelectual.

La alternancia reaparece en Aureliano pero al revés. Aunque desde el principio de la novela sabemos que va a ser coronel -lo que implica un cambio de nombre definitivo-, empieza investigando la platería, escribe versos y trata de descifrar los manuscritos de Melquíades. Su participación política está marcada por un hecho externo como lo había estado la intelectualización de su padre: se

\footnotetext{
${ }^{9}$ En todo caso, si se quisiera enfocar la novela desde una perspectiva de género, la división sexual está en el orden narrativo, en el hecho de que los personajes femeninos cumplan la función de complementar u oponerse a los masculinos, en un plano secundario.
} 
hace liberal porque es testigo del fraude de los conservadores. El vínculo de Aureliano con la política es ético. Más adelante se enfrenta con Alirio Noguera aunque sea liberal porque lo califica de "matarife", jura proteger a Moscote pero se vuelve a enfrentar a los conservadores porque matan a una mujer en la calle. Su segunda intervención política, contra la bananera, está marcada por el mismo espíritu: sólo busca la "guerra total" (García Márquez 208) después del asesinato de sus hijos. La contradicción político-intelectual es en realidad una declaración de principios, la formulación de un modelo en el que el intelectual deja sus tareas específicas ante la urgencia de los hechos. ${ }^{10} \mathrm{Su}$ función política dentro del pueblo la delega en Arcadio, que así recibe una doble herencia: de su tío, el mandato de ocuparse del pueblo -“Ahí te dejamos Macondo [...]. Te lo dejamos bien, procura que lo encontremos mejor" (García Márquez 92)- y de Melquíades, la educación. Tal vez por ser un Arcadio, es un desastre en las dos funciones. Como intelectual se hace maestro de la escuela que se funda en Macondo a instancias de Moscote pero no adelanta nada en el desciframiento de los manuscritos; como político se vuelve cruel y es Úrsula la que termina por hacerse cargo del gobierno.

El cruce de funciones entre arcadios y aurelianos se da con sus hijos gemelos, que invierten los roles. No es Aureliano Segundo sino José Arcadio Segundo el que se dedica a los manuscritos y le imprime un nuevo matiz a la relación con la política: la vida intelectual es un refugio, como los versos que escribía el coronel durante y después de la guerra. La participación política que le toca ya no es la organización del pueblo ni la guerra civil sino la rebelión contra la bananera: deja de ser capataz para tomar partido por los trabajadores (una opción ética, como las del coronel) que suben al monte armados con sus machetes (lo que sólo puede leerse como figuración de la guerrilla). José Arcadio Segundo usa el cuarto de Melquíades para esconderse después de esa aventura y es ese espacio el que lo transforma en un intelectual "iluminado por un resplandor seráfico"

10 Sin entrar en detalles que pecaran de excesivos o de biograficistas, éste es el modelo de intelectual dentro del que se puede pensar a García Márquez, cuyos compromisos políticos, desde la Revolución Cubana hasta el chavismo, han sido más éticos y humanitarios que militantes. 
(García Márquez 264) que va a dar pasos fundamentales en el desciframiento de los manuscritos. La oposición más interesante con su hermano Aureliano Segundo no es que éste deje la actividad intelectual por los amores de Petra Cotes sino que también usa la actividad mental como refugio pero sin pasar antes por la política. Aureliano se encierra a leer algo que parece ser Las mil y una noches para no ver los fusilamientos - que de paso es el primer momento en que se diferencia de su hermano. Ese no ver es el opuesto casi exacto a la función política que José Arcadio retiene como intelectual, repetir incesantemente que fueron 3000 los muertos en la huelga contra la bananera. Política e intelectualidad no se oponen como mente-cuerpo sino que encuentran formas de articularse, de combinarse que son las que definen el quehacer intelectual como algo más que la pura actividad mental. $^{11}$

En Conversación en la Catedral tampoco hay intelectuales "puros". Incluso cuando Santiago pretende alejarse del mundo escribiendo las editoriales banales, además de cumplir una función intelectual degradada no logra evitar que la "mundaneidad" (Said) se cuele en sus textos, que la relación de estos con el mundo se le vuelva en contra hasta en lo más trivial, que es el secuestro de su perro. ${ }^{12}$ El problema es que Santiago ha claudicado de su función intelectual. El periodismo es para él lo que la perrera es para Ambrosio, resignación. Por otro lado, cuando Santiago deja el compromiso con el pueblo porque no puede ser parte de él, revela una contradicción fundante del intelectual comprometido que aparece en palabras de su hermano: "si lo que quieres es volverte cholo, por qué no te haces sirviente más bien." (Vargas Llosa, Conversación 85) El problema es de clase más que de función - como les sucedía a los Buendía-; el fracaso de

${ }^{11}$ Hay dos figuras liminares entre los Buendía. Aureliano Triste (uno de los diecisiete hijos de Aureliano José), quien "Concebía los proyectos más desatinados como posibilidades inmediatas [...] y los llevaba a término sin intermedios de exasperación” (García Márquez 190), es el empresario. En el extremo opuesto, José Arcadio, que estaba destinado a ser cura, se vuelve bohemio en las buhardillas de París (como un personaje cortazariano al que se remite más o menos veladamente). Su destino utópico y el real le dan una formación intelectual alejada de la política y de la realización de cualquier tipo de proyecto.

12 Said entiende la "mundaneidad" como el modo en que el mundo real - la política, la vida humana- ingresa al texto y las relaciones que se establecen entre lo textual y lo extratextual. 
Santiago reside en que no puede superar sus contradicciones. Frente al pueblo, asume la incomprensión; frente a la familia burguesa, el rechazo: deja de verlos, no acepta trabajar en las empresas del padre, se niega a recibir su herencia porque “no quiero vivir mejor.” (609) Para José Miguel Oviedo (1997), los intelectuales en Vargas Llosa son siempre marginales; fracasan porque se rebelan pero no pueden acomodarse nunca. Lejos de transformarlo en una conciencia crítica, la imposibilidad de tomar partido es, sin importar cuál sea el bando, lo que hace que se "joda". "Borracheras sin convicción, Zavalita, polvos sin convicción, periodismo sin convicción. Deudas a fin de mes, una purgación lenta, inexorable inmersión en la mugre invisible.” (383)

Santiago queda a medio camino: no hace alianza con el pueblo, ni vuelve a su burguesía. El fracaso del ideal burgués aparece en la comparación con los otros: "Piensa: la promoción. Los cachorros que ya eran tigre y leones, Zavalita. Los ingenieros, los abogados, los gerentes. Algunos se habrían casado ya, tendrían queridas ya." (495) La formulación, que recuerda al final de Los cachorros, cambia de significado porque en el caso de Santiago todas las marcas vienen de elecciones propias - no de la fatalidad de la mordida del perro que emascula a Pichulita Cuéllar- y responden a ese lugar intermedio del que sus propias contradicciones no lo dejan salir. Santiago es un intelectual porque fracasa como militante, o al revés, fracasa como militante porque es un intelectual, porque duda cuando hay que actuar. "Yo sabía que si todos se dedicaran a ser inteligentes y a dudar, el Perú andaría siempre jodido." (150) El punto de comparación es su amigo Popeye. A punto de casarse, arquitecto, con proyectos de empresario, Popeye es miembro de la burguesía triunfante. Ni el compromiso político que le falta a Santiago queda afuera: Popeye apoya activamente a Belaunde y a la Acción Popular. La novela señala el fin de un modelo de intelectual. La política y la actividad mental que reunían los Buendía acá se escinden marcadamente; no sólo corresponden a dos etapas de la vida sino que una se abandona en nombre de la otra, no hay modos de articulación. 


\section{Biografias intelectuales}

Las dos novelas definen modelos intelectuales en la forma en que sus personajes intelectuales resuelven la materia a la que se enfrentan: los manuscritos de Melquíades en Cien años; la masa discursiva, la dispersión informativa de los diálogos de Conversación. No es que el desciframiento establezca un modelo en un sentido programático, un deber ser que permita hacer lo que un intelectual tiene que hacer. Al contrario, las dos novelas muestran el fracaso intelectual o mejor dicho, al intelectual como fracasado lo que, sin embargo, presenta una posible resolución de las contradicciones planteadas anteriormente; cómo Santiago vuelve a adentrarse en el mundo del que buscaba evadirse, en dónde confluye la alternancia y la superposición de la actividad mental y la política de los Buendía.

En Conversación, lo que conduce a la resolución de la contradicción es el mismo hecho que lleva al desenlace de la novela. De la sección editorial, Santiago pasa a los policiales. El entretenimiento o al menos el cambio de aire que promete la investigación del asesinato de Hortensia lo lleva a develar las causas de la ruina de su padre que resulta ser el autor intelectual del asesinato, que es a su vez la punta del ovillo de intrigas personales y políticas que están en la base de la novela- cuándo se jodió él, cuándo se jodió el Perú. La investigación remite a González Prada: "hay que seguir escarbando hasta que salte pus" (Varas Llosa, Conversación 358) le dice Becerrita, su jefe y guía en el mundo de los policiales, a Santiago; en el Perú “donde se aplica el dedo brota pus” decía González Prada (107). El diagnóstico es el mismo aunque cambien las circunstancias. ${ }^{13}$ Hay, sin embargo, una diferencia crucial. González Prada demandaba que el intelectual escribiera contra la "enfermedad" del Perú -en sus términos positivistas que ya deberían estar superados para la década del '60 dejando al "pus" en pura metáfora-. Y escribir significaba actuar; el intelectual tiene que denunciar para

\footnotetext{
${ }^{13}$ El texto de González Prada, de 1888, tenía como trasfondo y referencia constante los sucesos inmediatamente posteriores a la Guerra del Pacífico (1879).
} 
“contrarrestar el influjo del mal político" (González Prada 107) y además hablarle a las masas para llevarlas a la acción. Eso era la "Propaganda y ataque" que daba nombre al texto. En la novela se repite la comprobación de González Prada suponer que el "pus" aparecerá es suponer que siempre está- pero se la lleva fuera de la política y se le resta la solución. ${ }^{14}$

En la misma línea, al recibir el Rómulo Gallegos en 1967, Vargas Llosa (“La literatura..." 19) sostenía que la función del escritor (del intelectual, en el sentido sartreano) era "la protesta, la contradicción y la crítica." Santiago muestra el límite. El desciframiento es posible porque lo político está tramado con lo personal, la historia del crimen de Hortensia es la historia de la familia de Santiago. Pero saber que su padre es el autor intelectual del crimen de Hortensia no conduce a nada más que a la frustración: ni puede llevar a una resolución dentro de la lógica policial porque el crimen se resuelve desde el periodismo - y no el tipo de periodismo que maneja nociones de justicia- ni puede llevar a una "denuncia" de corte político porque finalmente el crimen que había puesto en juego a tantos personajes vinculados al poder pertenece a la esfera de lo privado donde también se queda el descubrimiento de Santiago. El fracaso no es que el intelectual sea sólo el que descifra, sino que no haga nada con la verdad que descubre. Esto se entiende en el marco de una novela pesimista que termina con Ambrosio diciendo “después ya se moriría ¿no, niño?” (Vargas Llosa, Conversación 620) La pregunta por cómo se jodió el Perú los compromete a todos. En uno u otro momento todos se jodieron y no hay casi ninguna posibilidad de revertir esa realidad. El intelectual es el único sujeto capacitado para desentrañar la trama de sucesos que constituyen la ruina personal y nacional; puede escuchar, combinar relatos y desentrañar la verdad, pero no produce ni cambia nada porque se niega a hacerlo.

El mismo problema aparece en la actividad de descifrar los manuscritos de

\footnotetext{
${ }^{14}$ Por otro lado, en Conversación esa constatación emana de una actividad intelectual menor -el periodismo en la sección de policiales, de acuerdo con la novela - y sobre un personaje también degradado - una prostituta.
} 
Melquíades. Le lectura de la profecía en el mismo momento en que se está cumpliendo el último hecho de la serie hace que los esfuerzos de todos los Buendía desde el principio de los tiempos (de la novela) parezcan inútiles. El problema, sin embargo, no se plantea como tal porque hay una propuesta de futuro, la ciudad del sueño profético de Melquíades donde no hay ningún Buendía porque "las estirpes condenadas a cien años de soledad no tenían una segunda oportunidad sobre la tierra." (349) Habría que preguntarse entonces qué función tienen los intelectuales en esa historia que los excede, para qué sirven, para qué descifran un destino del que no puede salirse.

De acuerdo con Ludmer, Aureliano Babilonia recupera la unidad perdida al reunir las características y las funciones de aurelianos y arcadios. En principio esto no debería leerse como una virtud. De hecho, el verdadero último Aureliano, el de la cola de cerdo, "era un Buendía de los grandes, macizo y voluntarioso como los José Arcadio, con los ojos abiertos y clarividentes de los Aurelianos; y predispuesto para empezar la estirpe otra vez." (García Márquez 344) Su muerte, la clausura de la estirpe, es como una repetición anticipada de la destrucción final, protagonizada por su padre. La unidad que parece no lograrse nunca es la del intelectual y el político. Aureliano Babilonia está siempre al margen de los acontecimientos de su tiempo; en parte porque la decadencia de Macondo implica que ya no pasa nada y en parte porque es el que lleva al extremo la idea de la vida intelectual como refugio y de su materialización, el laboratorio, como torre de marfil intocada por el tiempo y los desastres naturales. El aislamiento es parte de su formación: como Fernanda no lo deja ir a la escuela aprende con los relatos inventados que Aureliano Segundo arma a partir de las imágenes de la enciclopedia que había comprado para Meme. Lo que llama la atención de Aureliano Babilonia es, justamente, la disparidad entre lo que sabe y el contacto que tiene con el mundo; no sabe nada de su tiempo pero tiene los conocimientos del hombre medieval y, mucho más importante, conoce toda la historia de Macondo incluso antes de descifrar los pergaminos - su frase es "Todo se sabe." (García Márquez 314) 
La virtud de Aureliano no es tanto el estudio como la clarividencia: "no compraba los libros para informarse sino para verificar la exactitud de sus conocimientos." (García Márquez 320-321) Esta es, por otro lado, la misma forma en que Amaranta Úrsula lee las revistas de moda. La capacidad de ver el futuro está en la familia. José Arcadio tuvo un sueño profético -paralelo al de Melquíades-; el coronel tenía premoniciones y Pilar Ternera vivía de tirar las cartas. El hecho paradójico de que la profecía sólo se pueda leer cuando es el relato del pasado abre otra serie, que es la de los historiadores: las fichas para la máquina de la memoria de José Arcadio Buendía, los poemas de Aureliano en los que "resolvió en versos rimados sus experiencias a la orilla de la muerte" (García Márquez 119) e incluso las cartas que escribe Fernanda y que son la historia privada de la familia. Allí están contenidas las funciones de la escritura. Las fichas conservan la memoria, las cartas de Fernanda revelan verdades ocultas, los versos de Aureliano le permiten comprender: "sus pensamientos se hicieron tan claros, que pudo examinarlos al derecho y al revés.”(119) Si José Arcadio descubre la identidad de Aureliano Babilonia en las cartas de Fernanda, él entiende la historia y el destino de todos en los manuscritos de Melquíades. Como en Conversación, la tarea del intelectual tiende al pasado, por eso la profecía completa la serie de las historias.

Cuando analiza esta cuestión, Ángel Rama ubica a Melquíades como escritor y a Aureliano como crítico ${ }^{15}$. El foco está en la función. El intelectual como lector del mundo sólo puede desentrañar las catástrofes personales, familiares, nacionales pero nunca prevenirlas ni revertirlas. El problema de Aureliano Babilonia es generacional. Si en el pasado los intelectuales eran también fundadores de la nación (José Arcadio Buendía), actores políticos de la

\footnotetext{
${ }^{15}$ Se puede reconstruir una controversia sobre el lugar de Melquíades como escritor. De acuerdo con Rama, es el autor de la novela porque cuenta la historia hacia adelante. Para Rodríguez Monegal, el autor sería Aureliano Babilonia transformado en Melquíades después de la lectura. En rigor, ni la escritura ni la lectura de los pergaminos pueden ser el libro porque su estructura temporal no coincide con el relato en un presente permanente hecho por Melquíades. La única versión que responde a esos parámetros es el modo en que, hacia el final de su vida, Úrsula actúa el pasado confundiendo a los miembros de la familia con los antepasados homónimos.
} 
organización nacional (el coronel Aureliano Buendía fundamentalmente) $\mathrm{u}$ organizadores de las masas de trabajadores contra la dominación imperial (como José Arcadio Segundo en la huelga contra la bananera), Aureliano Babilonia llega en el momento de la autonomización del trabajo intelectual. No es que las otras esferas se separen de ella progresivamente, como sucedió durante la modernización latinoamericana, sino que todo lo demás desaparece. El laboratorio de Melquíades, torre de marfil degradada, "cuarto mágico" para Rodríguez Monegal donde antes no entraba el polvo, ahora es lo último que queda por destruir. Dentro queda el intelectual enfrentado al peligro de perder su función.

Este aislamiento es selectivo. Aunque desconoce los acontecimientos de su tiempo, Aureliano Babilonia reparte su vida entre los manuscritos, los amores con Amaranta y el grupo de amigos y colegas intelectuales. Por un lado, recupera la unidad mente-cuerpo (Ludmer). Por otro, introduce algo nuevo, que es la cofradía intelectual organizada en torno al librero que es su maestro en ausencia del maestro de todos los demás que era Melquíades (un catalán en vez de un gitano, siempre un extranjero). Él tampoco tiene contacto con el mundo exterior -en vez de un laboratorio tiene la librería- y lo único que hace es escribir otro texto misterioso (en hojas sueltas de cuaderno, también opuestas a los pergaminos de Melquíades) que nunca nadie llega a descifrar porque se lo lleva con él de regreso a Europa. El librero espeja a Melquíades - la extranjería, el espacio, la escritura- y también a Aureliano; es el modelo del intelectual como lector. Lee porque hay algo que leer, hay libros que no estaban en el caso de Melquíades, y se dedica exclusivamente a eso. Cambia el maestro, cambia el espacio de sociabilidad, cambia la relación con el mundo: Aureliano Babilonia descifra porque es diferente, porque la función intelectual ha cambiado. Pero descifra también porque es el último, es imprescindible llegar a ese desarrollo de la actividad intelectual para hacer inteligible lo que está doblemente codificado. La función intelectual está ligada a la memoria, de ahí la serie de escritores de textos que conservan la memoria dentro de la que Ludmer y Volkening ubican la novela. Aureliano Babilonia no puede cambiar lo que está escrito pero el desciframiento 
CATEDRAL TOMADA: Revista de crítica literaria latinoamericana / Journal of Latin American Literary Criticism El Boom y el fracaso de los intelectuales. Sobre Conversación en la Catedral (1969) de Vargas Llosa y Cien años de soledad (1967) de García Márquez

es, en sí mismo, la unidad entre la actividad mental y la política. Lo que Aureliano Babilonia lee en el manuscrito es como la verdad de los muertos en la huelga que repiten él y Aureliano Segundo, lo que necesita ser dicho. El fracaso de la acción es la constatación de la especificidad de la tarea intelectual: la memoria es una versión del pasado que apunta hacia el futuro.

\section{Conclusión: dos opciones en torno a la lectura}

Santiago está situado después de esa diferenciación de las funciones del intelectual. Ya cerrado el primer ciclo de novelas y quince años más tarde, Santiago Zavala reaparece en Kathie y el hipopótamo, donde revisita sus convicciones antiburguesas, ahora vaciadas de todo contenido político. La definición que se hace de él resulta significativa: "Un hipopótamo que parece terrorífico pero que sólo come pajaritos." (Vargas Llosa, Kathie 184) El intelectual -o al menos ese modelo de intelectual - no sirve para nada porque no implica un peligro para nadie. Por el contrario, el intelectual en el Perú deviene escriba sujeto a los caprichos de una burguesa delirante $-\mathrm{y}$ cambia su nombre a Mark Griffith porque "los nombres peruanos no parecen de escritores." (129) Significativamente, Santiago Zavala, que era incapaz de comprender el trabajo de Ambrosio en la perrera, alcanza el mismo nivel, aunque desde la especificidad de lo único que sabe hacer, escribir. Él también vive a la sombra de una burguesía improductiva, él también tiene sólo su fuerza de trabajo para vender, él también, finalmente, se resigna a hacer lo único que le garantiza la supervivencia. De este segundo final de Santiago Zavala surge otra problemática, que Vargas Llosa trabaja a partir de la figura de Sebastián Salazar Bondy. El escritor en el Perú no puede ser un profesional porque no hay público, siempre tiene que vivir de otras actividades y es necesariamente un frustrado que tiende a desertar (Vargas Llosa, “Sebastián Salazar Bondy...”).

La historia de Santiago en Conversación puede leerse como la narración de esa idea; la deserción inicial (la poesía) arrastra todas las que siguen. El 
periodismo entendido como una actividad subsidiaria es, sin embargo, una actividad intelectual que lo devuelve una y otra vez al mundo del que quiere escaparse. El episodio de la perrera es una prefiguración de los efectos de la escritura, la develación de la verdad sobre su padre es la consumación del lugar del intelectual. A pesar de dedicarse a una forma de la escritura, Santiago también es un lector. La actividad de descifrar las palabras de los otros que comparte con Aureliano Babilonia lo lleva a un lugar similar: los dos descubren una verdad que los involucra personalmente -las dos son historias familiares- pero que también los excede porque intercalada con la historia privada está la historia de Macondo y la de la trastienda del gobierno de Odría. El mundo irrumpe en la tarea de los intelectuales; su única función se desprende de la capacidad para saber leerlo. Lo que queda inconcluso es qué pasa con lo que fue descifrado: qué hace Santiago frente a la verdad y cómo se conserva la memoria cuando se destruyen sus testigos.

En las dos novelas los intelectuales son lectores insertos en sociedades que tienden a la degradación. Macondo se destruye completamente; Vargas no puede hacer lo mismo con el Perú pero sí transformar la incertidumbre de los personajes- "el fin de Odría es el comienzo, ¿de qué?” (Conversación 317)- en una proyección del rechazo al populismo del presente -el gobierno de Velasco Alvarado. En una interpretación que abarca un segmento importante de novelas del Boom, Jean Franco señala que hay una disparidad entre los personajes individualizados -"entrepreneurs" los llama- y las circunstancias a las que permanecen atados, que los determinan. Aunque los desastres finales están fuera del ámbito de acción de los dos, lo que opone a Santiago y a Aureliano son sus elecciones; qué hacen con sus lecturas. Vale la pena tener en cuenta que el modelo intelectual más frecuentado entre estos escritores del Boom es la teoría del compromiso propuesta por Sartre ${ }^{16}$. Y es especialmente útil en el caso de Vargas,

\footnotetext{
${ }^{16}$ Evidentemente no es el lugar para explicarla. En líneas generales el compromiso supone que el escritor, en tanto libertad situada, es absolutamente responsable de todo lo que dice o calla porque el lenguaje (entendido como comunicación) es su campo de trabajo, su esfera de acción. Véase Jean Paul Sartre. ¿Qué es la literatura? (Situations II). Buenos Aires: Losada, 2003.
} 
que comienza la novela con una dedicatoria en la que se autodenomina "sartrecillo valiente" y la termina con un intelectual que decide mantener la verdad en secreto. Cien años de soledad, en cambio, es una apuesta por la escritura. El desciframiento cobra sentido porque permite que la historia de los Buendía - que es la historia de Macondo y del mundo- sobreviva a la destrucción de la estirpe. Aureliano Babilonia no triunfa porque logre superar la doble codificación del texto sino porque cumple con su tarea, que es la culminación del proyecto de todos los intelectuales Buendía y por lo tanto la definición de su función y su lugar en la sociedad, su responsabilidad. En términos sartreanos, ninguno tiene la capacidad para modificar la situación de su época - porque ya no están insertos en esas esferas de acción- pero son absolutamente responsables de lo que hacen frente a ella. Donde Santiago calla y oculta, Aureliano hace una lectura que revela. Los personajes muestran las líneas en las que se están pensando los intelectuales reales de la época. La oposición entre los dos no es sino el mismo intento por resolver la contradicción entre la palabra y la acción.

\section{Corpus}

García Márquez, Gabriel. Cien años de soledad. 1967. Barcelona: Círculo de lectores, 1975.

Vargas Llosa, Mario. Conversación en La Catedral. 1969. Buenos Aires: Alfaguara, 2005.

---. La señorita de Tacna. Kathie y el hipopótamo. Buenos Aires: Alfaguara, 2005. 


\section{Bibliografía citada}

Altamirano, Carlos. Intelectuales. Notas de investigación. Bogotá: Norma, 2006.

Bauman, Zygmunt. Legisladores e intérpretes. Sobre la modernidad, la posmodernidad y los intelectuales. 1995. Buenos Aires: Universidad Nacional de Quilmes, 2005.

Franco, Jean. "Modernización, resistencia y revolución. La producción literaria de los años sesenta". Escritura, III/ 3 (1977): 3-20.

González Prada. "Propaganda y ataque". Páginas libres. Horas de lucha. Caracas: Biblioteca Ayacucho, 1979. 101-111.

Ludmer, Josefina. Cien años de soledad. Una interpretación. 1972. http://www.josefinaludmer.com/Josefina_Ludmer/libros_files/Cien\%20an \%CC \%83os\%20de\%20soledad.pdf. 7 de febrero de 2014.

Oviedo, José Miguel. "Tema del traidor y del héroe: sobre los intelectuales y los militares de Vargas Llosa". Saúl Sosnowski, ed. Lectura crítica de la literatura americana. Actualidades fundacionales. Caracas: Biblioteca Ayacucho, 1997. 143-162.

Rama, Ángel. La narrativa de Gabriel García Márquez. Edificación de un arte nacional y popular. México: Colcultura, 1991.

Rodríguez Monegal, Emir. "One hundred years of solitude: the last three pages". Books Abroad, 47 / 3 (1973): 485-489.

Said, Edward W. El mundo, el texto y el crítico. 1983. Buenos Aires: Debate, 2004.

Sosnowski, Saúl, ed. Lectura crítica de la literatura americana. Actualidades fundacionales. Caracas: Biblioteca Ayacucho, 1997.

Vargas Llosa, Mario. "La literatura es fuego". Helmy F. Giacoman y José Miguel Oviedo, eds. Homenaje a Mario Vargas Llosa. Madrid: Anaya, 1971. 
CATEDRAL TomAdA: Revista de crítica literaria latinoamericana / Journal of Latin American Literary Criticism El Boom y el fracaso de los intelectuales. Sobre Conversación en la Catedral (1969) de Vargas Llosa y Cien años de soledad (1967) de García Márquez

---. "Sebastián Salazar Bondy y la vocación del escritor en el Perú" en Contra viento y marea I (1962-1972). Barcelona: Seix Barral, 1990. 111-135.

Volkening, Ernesto. "Anotado al margen de Cien años de soledad". Saúl Sosnowski, ed. Lectura crítica de la literatura americana. Actualidades fundacionales. Caracas: Biblioteca Ayacucho, 1997. 54-83. 